\title{
EFFECT OF ANTI-INFLAMMATORY DRUGS ON ENDOTOXIN-INDUCED DIARRHEA IN MICE
}

\author{
Kaito TSURUMI and Hajime FUJIMURA \\ Department of Pharmacology, Gifu University School of Medicine, \\ 40-Tsukasamachi, Gifu 500, Japan
}

Accepted September 27, 1982

\begin{abstract}
Prostaglandins (PGs) increase the intestinal fluid to result in diarrhea. Some laxatives are known to exert their actions partially by stimulating the PGs biosynthesis. On the other hand, it is well documented that nonsteroidal anti-inflammatory drugs (NSAID) inhibit markedly the PGs biosynthesis. Since endotoxin (ETX) also produces diarrhea similarly in all species of experimental animals, we investigated the effect of various NSAID and steroidal anti-inflammatory drugs (SAID) on ETX-induced diarrhea in mice. ETX given p.o. did not produce diarrhea, but it could induce it after parenteral administration, especially intravenous injection. All NSAID and SAID tested inhibited ETX-induced diarrhea at dose levels similar to or lower than those commonly producing an acute anti-inflammatory effect. The anti-diarrheal effects were found in not only acidic NSAID. but also in basic NSAID and SAID which did not inhibit ultraviolet erythema, acute death induced by arachidonic acid injection and PGs biosynthesis. Therefore, this test using ETX-induced diarrhea in mice may be used as a new and desirable method for screening or evaluating anti-inflammatory drugs. The mechanism of diarrhogenic action of ETX is poorly understood, but may be attributed to inhibition of PGs biosynthesis besides other unknown actions.
\end{abstract}

The most widely accepted mechanism of action of non-steroidal anti-inflammatory drugs (NSAID) is the inhibition of prostaglandins (PGs) biosynthesis. One of the biological actions of PGs is to induce diarrhea, this being the most prominent side effect of PGs used to terminate pregnancy. PGs inhibit absorption and cause the secretion of water and electrolytes in the intestinal lumen of man and other species of animals (1-4). Similarly to PGs, laxatives such as senna (5), anthraquinones (6), diphenolic derivatives (7) and ricinoleic acid (8) are reported to inhibit the intestinal absorption of water and electrolytes, causing the increased net secretion. Beubler and Juan (9) assumed that the action of non-osmotic laxatives is partially mediated by $\mathrm{PGE}_{2}$, although other mechanisms also seem to be involved in their mode of action. It is known that ricinoleic acid, an active component of castor oil. accumulates fluid in the intestinal lumen. As the intestinal effect of ricinoleic acid relating to that of PGs, Awouters et al. (10) investigated the effects of NSAID on castor oil-induced diarrhea, and concluded that delay of castor oil-induced diarrhea in rats is a new way to evaluate the effect of PGs biosynthesis inhibitors.

On the other hand, endotoxin (ETX) causes diarrhea in all species of animals (11). It can release some mediators such as histamine, serotonine, PGs and lymphokine. Fletcher and Ramwell (12) reported the increase in plasma PGs concentration following the i.v. administration of ETX and its 
prevention by NSAID. On the basis of their research, we tried to investigate the effect of NSAID and steroidal anti-inflammatory drugs (SAID) on diarrhea induced by ETX instead of castor oil in mice. The correlation between the protective effect of these drugs on ETXinduced diarrhea and the inhibitory effect on ultraviolet erythema in guinea pigs or on acute death of rabbits by i.v. injection of arachidonic acid which may be related to the inhibition of PGs biosynthesis was discussed in the present paper.

\section{Materials and Methods}

\section{Drugs and chemicals}

The diarrhogens used were ETX, lipopolysaccharide (E. coli, 0111: B4, Difco Laboratories), pilocarpine (Nakarai Chemicals, Ltd.), serotonin (Wako Pure Chemical Industries, Ltd.), sennoside (Nippon Funmatsu Yakuhin Co.), arachidonic acid ( $\mathrm{P}-\mathrm{L}$ Biochemical lnc.) and $\mathrm{PGE}_{2}$ (Ono Pharmaceutical Co., Ltd.). These compounds were dissolved in physiological saline solution immediately before use, except for arachidonic acid which was suspended in a $7 \%$ solution of Nikkol-HCO 60 (Nihon Chemical Co., Ltd.).

Diclofenac-Na, flurbiprofen, pirprofen, suprofen, isoxepac, CN-100 [2-(10, 11dihydro-10-oxo-dibenzo b. $f$ thiepin-2-yl)propionic acid], indomethacin, pranoprofen, ketoprofen, AHR-5850 (sodium 2-amino-3benzoyl-benzen acetate monohydrate), clidanac, benoxaprofen, ibuprofen, flufenamic acid, suxibuzone, phenylbutazone, mefenamic acid, feprazone, aspirin, ketophenylbutazone and oxyphenbutazone were used as acidic NSAID. Proquazone, GP-53633 [2-tertiarybutyl-4(5)-phenyl-5(4) - (3-pyridyl) -

imidazole], tiaramide- $\mathrm{HCl}$, mepirizole, isoxal. benzydamine- $\mathrm{HCl}$ and aminopyrine were used as basic NSAID. The SAID tested were dexamethasone and predonisolone. All test drugs were suspended in a $0.5 \%$ tragacanth gum solution.

\section{Methods}

1. Diarrhogenic effect of ETX in mice: The diarrhogenic effect was examined according to the procedure reported in a previous paper (13). Male dd strain mice, weighing 18-20 g. were given diet and water ad libitum before experiment, but not during testing. The animals were individually placed in a box with 20 compartments, the bottom of which was covered with a sheet of filter paper to facilitate the observation of the fecal state. Two hr later, the animals showing spontaneous diarrhea were excluded. ETX was administered via various routes in only normal mice without spontaneous diarrhea. After administration of ETX, the diarrhogenic effect was evaluated 4 times at 1 -hr intervals. The filter paper was exchanged after each evaluation. The formless and liquid stool with a stain on the filter paper was regarded as diarrhea. The result was expressed by the number of diarrheal animals/animals tested. Each group consisted of 10 mice in all experiments.

2. Effect of some aspirin-like drugs on diarrhea induced by ETX and other diarrhogens in mice: Male mice of the same strain and body weight as mentioned above were used. After mice with spontaneous diarrhea were excluded by pre-observation for $2 \mathrm{hr}$ under the untreated condition. various doses of aspirin-like drugs such as diclofenac-Na, indomethacin, phenylbutazone and aspirin were administered p.o. Thirty min later, mice were administered each diarrhogen in a dose that induced diarrhea: ETX was given i.v., $2 \mathrm{mg} / \mathrm{kg}$; pilocarpine s.c.. $6 \mathrm{mg} / \mathrm{kg}$; serotonin s.c., $10 \mathrm{mg} / \mathrm{kg}$ : PGE s.c., $1.5 \mathrm{mg} / \mathrm{kg}$; and sennoside p.o., $20 \mathrm{mg} / \mathrm{kg}$. After $2 \mathrm{hr}$, with the exception of $6 \mathrm{hr}$ for sennoside, the effect of these diarrhogens was evaluated.

3. Effect of NSAID and SAID on ETXinduced diarrhea in mice: The effect of acidic 
and basic NSAID and SAID on ETX-induced diarrhea was assessed in the same manner as the case of aspirin-like drugs. ED50 in the anti-diarrheal effect of each drug was calculated by the method of Litchfield and Wilcoxon.

4. Effect of NSAID and SAID on ultraviolet erythema in guinea pigs: In groups of 5 male guinea pigs weighing $300-350 \mathrm{~g}$. the test was carried out according to the method described by Winder et al. (14). The skin of each animal was depilated at the ventro-lateral side $24 \mathrm{hr}$ before the test. An adhesive tape with 3 small holes was applied on the depilated skin. Then the animals were irradiated with ultraviolet rays of a $400 \mathrm{~W}$ mercury lamp at a distance of 20 $\mathrm{cm}$ for $40 \mathrm{sec}$. Two hr later, the degree of erythema was scored as 1.0 (erythema with clear border). 0.5 (erythema with unclear border) and 0 (negligible erythema). The drug was regarded as effective when the total score of 3 areas was below 1.5. A half dose of a test drug was given i.p. $1 \mathrm{hr}$ before irradiation, and the remaining half given immediately after irradiation.

5. Effect of NSAID and SAID on acute death by arachidonic acid in rabbits: The i.v. injection of $1.4 \mathrm{mg} / \mathrm{kg}$ of arachidonic acid in rabbits causes acute death within a few min (15). Male rabbits weighing $2.5-3.0 \mathrm{~kg}$ received p.o. each anti-inflammatory drug. Two hr later, arachidonic acid was administered i.v. to observe the protective effect from acute death. The minimum protective dose of each drug was calculated by the up and down method.

\section{Results}

1. Diarrhogenic effect of ETX in mice: ETX induced diarrhea dose-dependently in mice by i.v.. i.p. and s.c. administration, but did not induce it by p.o. administration (Table 1). ETX could induce the symptom in most of the animals up to $1 \mathrm{hr}$ after injection via any route except for p.o. and in a few

Table 1. Diarrhogenic activity of endotoxin in mice

\begin{tabular}{|c|c|c|c|c|}
\hline \multirow{3}{*}{ Route } & \multirow{3}{*}{$\begin{array}{l}\text { Doso } \\
\mathrm{mg} / \mathrm{kg}\end{array}$} & \multirow{3}{*}{$\mathrm{n}$} & \multicolumn{2}{|c|}{ Diarrheal \% } \\
\hline & & & \multicolumn{2}{|c|}{ Time (hr) after endotoxin } \\
\hline & & & 1 & 2 \\
\hline \multirow{6}{*}{ i.v. } & 2.0 & 10 & 90 & 100 \\
\hline & 1.0 & 10 & 80 & 80 \\
\hline & 0.5 & 10 & 70 & 70 \\
\hline & 0.2 & 10 & 50 & 60 \\
\hline & 0.1 & 10 & 40 & 50 \\
\hline & 0.05 & 10 & 20 & 30 \\
\hline & 2.0 & 10 & 60 & 80 \\
\hline \multirow{5}{*}{ i.p. } & 1.5 & 10 & 50 & 70 \\
\hline & 1.0 & 10 & 30 & 50 \\
\hline & 0.75 & 10 & 40 & 40 \\
\hline & 0.5 & 10 & 20 & 30 \\
\hline & 0.2 & 10 & 0 & 0 \\
\hline \multirow{4}{*}{ s.c. } & 2.0 & 10 & 40 & 40 \\
\hline & 1.5 & 10 & 20 & 20 \\
\hline & 1.0 & 10 & 0 & 10 \\
\hline & 0.5 & 10 & 0 & 0 \\
\hline \multirow{2}{*}{ p.o. } & 4.0 & 10 & 0 & 0 \\
\hline & 2.0 & 10 & 0 & 0 \\
\hline
\end{tabular}


animals, from 1 to $2 \mathrm{hr}$. The diarrhogenic activity of ETX was the most potent by i.v. administration, followed by the i.p. and s.c. routes. With doses over $2 \mathrm{mg} / \mathrm{kg}$. ETX produced diarrhea in all mice up to $2 \mathrm{hr}$ after i.v. injection.

2. Effect of aspirin-like drugs on diarrhea induced by ETX and other diarrhogens in mice: The effect of typical NSAID, viz., diclofenac-Na, indomethacin, phenylbutazone and aspirin, were first examined on diarrhea induced by the i.v. injection of $2 \mathrm{mg} /$ $\mathrm{kg}$ ETX. The drugs inhibited diarrhea dosedependently at doses lower than those which could exert an anti-inflammatory effect. The $50 \%$ protecting dose from diarrhea (ED50) was calculated for each drug (Fig. 1). Next, the effect of these aspirin-like drugs on diarrhea induced by other diarrhogens such as pilocarpine, 5-HT, $P G E_{2}$ and sennoside was examined in mice. The aspirin-like drug markedly inhibited only ETX-induced diarrhea, but not the diarrhea induced by other diarrhogens (Table 2). On the contrary. atropine in a high dose and morphine inhibited the diarrhea induced by all diar- rhogens tested. Atropine in a low dose inhibited completely the diarrhea induced by pilocarpine and incompletely that induced by $\mathrm{PGE}_{2}$ or ETX. This suggests that atropine in a high dose and morphine should nonspecifically inhibit the intestinal movement and so inhibit diarrhea. Methysergide. 20 $\mathrm{mg} / \mathrm{kg}$, partially inhibited the diarrhea induced by $5-H T, P G E_{2}$ and ETX.

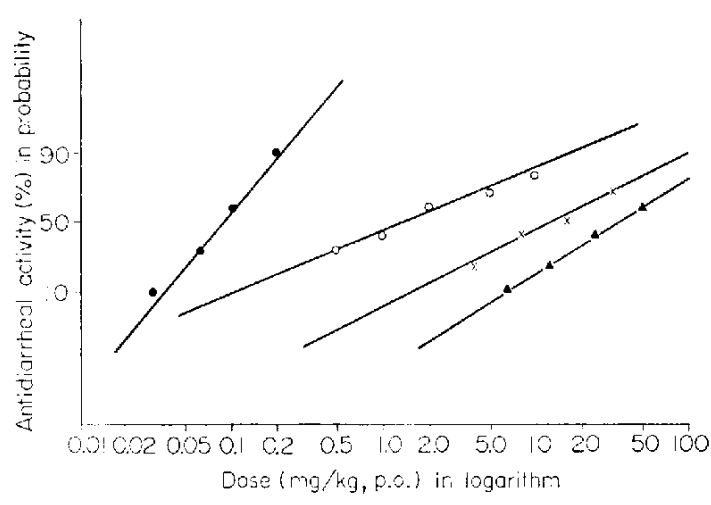

Fig. 1. Dose response of inhibitory effect of antiinflammatory drugs at $2 \mathrm{hr}$ on endotoxin-induced diarrhea in mice. Diclofenac- $\mathrm{Na}, \mathrm{O}-\mathrm{O}$ Indomethacin, $\times-\times$ Phenylbutazone, Aspirin.

Table 2. Anti-diarrheal effects of anti-inflammatory drugs and reference drugs on various diarrhogens in mice

\begin{tabular}{|c|c|c|c|c|c|c|c|}
\hline \multirow{3}{*}{ Drugs } & \multirow{3}{*}{$\begin{array}{l}\text { Dose } \\
\mathrm{mg} / \mathrm{kg}\end{array}$} & \multirow{3}{*}{ Route } & \multicolumn{5}{|c|}{ Anti-diarrheal effect $(\%)^{*}$} \\
\hline & & & \multicolumn{5}{|c|}{ Diarrheal-inducing agents } \\
\hline & & & Pilocarpine & 5-HT & $P G E_{2}$ & ETX & Sennoside \\
\hline Diclofenac- $\mathrm{Na}$ & 1.0 & p.o. & 0 & 0 & 0 & 100 & 0 \\
\hline Indomethacin & 5.0 & p.o. & 0 & 0 & 0 & 70 & 0 \\
\hline Phenylbutazone & 50 & p.o. & 0 & 0 & 0 & 80 & 0 \\
\hline Aspirin & 100 & p.o. & 0 & 0 & 0 & 80 & 0 \\
\hline \multirow[t]{2}{*}{ Atropine } & 0.2 & s.c. & 100 & 0 & 30 & 50 & 0 \\
\hline & 5.0 & s.c. & 100 & 70 & 100 & 100 & 100 \\
\hline Methysergide & 20 & s.c. & 0 & 60 & 30 & 80 & 0 \\
\hline Morphine & 5.0 & s.c. & 100 & 100 & 100 & 50 & 100 \\
\hline
\end{tabular}

Drug was given p.o. and s.c. $30 \mathrm{~min}$ and $15 \mathrm{~min}$ prior to diarhogens, respectively, except for morphine which was given $3 \mathrm{hr}$ after sennoside. Pilocarpine (6 mg/kg. s.c.).5-HT (10 mg/kg. s.c.), PGE (1.5 mg/ $\mathrm{kg}, \mathrm{s}, \mathrm{c}$.) , ETX (endotoxin $2 \mathrm{mg} / \mathrm{kg}$, i.v.) and sennoside (15 $\mathrm{mg} / \mathrm{kg}, \mathrm{p} . \mathrm{o}$.) were used in a dose which could induce $100 \%$ diarrhea in normal mice. Effect was evaluated $1 \mathrm{hr}$ after diarrhogens with the exception of sennoside for which evaluation was made $6 \mathrm{hr}$ later. "No. of mice with normal feces/No. of mice tested (10). 


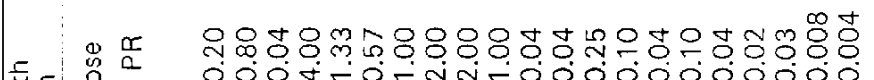

$\stackrel{\circ}{\circ} \stackrel{0}{0}$

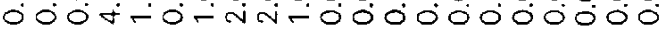

壱 E

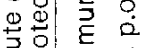

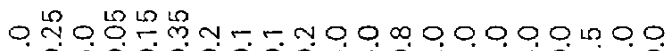

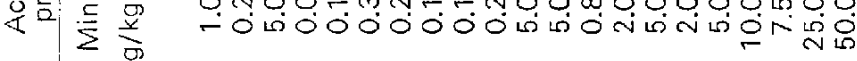

0.0

४⿻

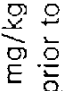

Lim 88889 $\wedge \wedge \wedge$

$\wedge \stackrel{\circ}{\Lambda}$

学 8

용요

$\circ \div$

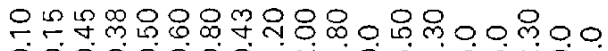

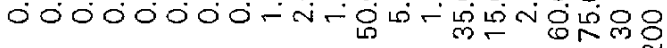
-

$*$
or
0

+ 吉云

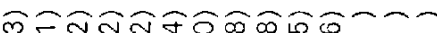

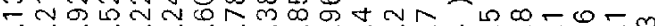

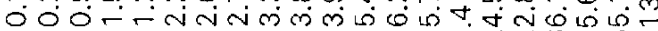

$111111111115 T \pi \%$

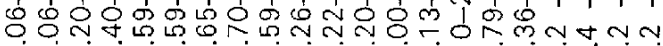

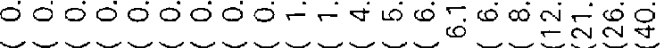

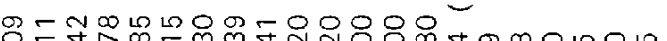

ல்0ல்-

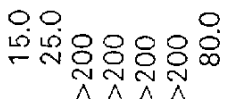

ㄴํㅇำ $\wedge \wedge \wedge$

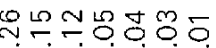

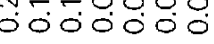

$\infty$

$\wedge \wedge$

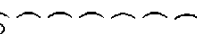

mogomm का Lin जi

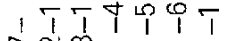

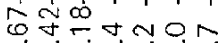
vंणm

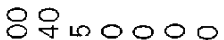

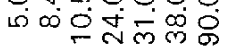

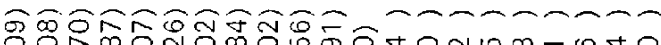
ODOD-NFN NOEN $\begin{array}{lllllllllll}1 & 1 & 1 & 1 & 1 & 1 & 1 & 1 & 1 & 1 & 1\end{array}$ Бㅇํㅇ m 000000000 - Nm

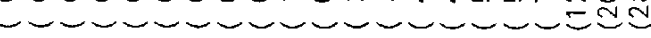

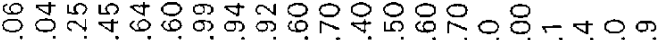

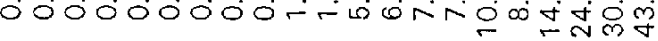

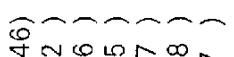

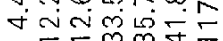

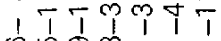
守 - लंखं $\sim \sim \sim E \Xi$

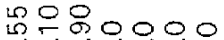

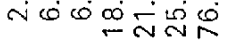

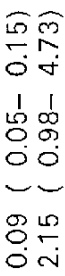

ติต On 息客

oNo ํㅜㅇ 용

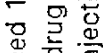
要范 ड 5

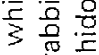
풍 $\sim$ है ㄴ.는 
3. Effect of NSAID and SAID on ETXinduced diarrhea in mice: The inhibitory effects of 30 kinds of NSAID and SAID on ETX-induced diarrhea were examined in mice. A considerable number of the drugs inhibited ETX-induced diarrhea evidently in doses similar to or lower than those exerting an anti-inflammatory effect. The ED50 values for all drugs calculated at 1 and $2 \mathrm{hr}$ after ETX challenge are listed in Table 3 in the order of decreasing potency, in addition to the relative potency of the drugs to indomethacin $(1.30 \mathrm{mg} / \mathrm{kg})$ at $2 \mathrm{hr}$ after administration of ETX.

4. Effect of NSAID and SAID on ultraviolet erythema in guinea pigs and acute death by i.v. injection of arachidonic acid in rabbits: It is well known that aspirin-like drugs, viz., PGs biosynthesis inhibitors. markedly inhibit ultraviolet erythema in guinea pigs and acute death of rabbits by injection of arachidonic acid. In this test, all acidic and some basic NSAID markedly inhibited both reactions. The activities and potency ratios of the drugs to indomethacin are listed in Table 3. The relative potency of the effective drugs (19 acidic and 3 basic NSAID) in

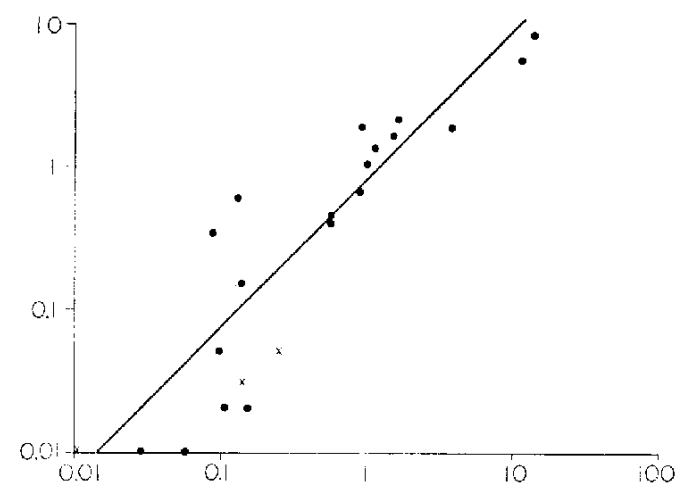

Fig. 2. Correlation between the relative potencies of NSAID in the ETX-induced diarrhea test in mice and the ultraviolet erythema test in guinea pigs. Ordinate: Potency ratio vs. indomethacin in the ultraviolet erythema test. Abscissa: Potency ratio vs indomethacin in the ETX-induced diarrhes test. $0=$ Acidic NSAID, $x=$ Basic NSAID. antierythema reaction correlated well with relative protective potency of these drugs on ETX-induced diarrhea. The regression line between the relative anti-erythema and antidiarrheal potencies of the drugs was not different statistically from the line of equal activity in both tests as shown in Fig. 2 $[r=0.796, \log Y=(1.05 \log x)-(0.17)]$. On the other hand, most of the basic NSAID and all SAID did not inhibit both reactions, in spite of potent inhibition of ETX-induced diarrhea.

\section{Discussion}

Not only acidic NSAID of aspirin-like drugs but also basic NSAID and SAID effectively inhibited ETX-induced diarrhea in mice at doses similar to or lower than those commonly producing an acute antiinflammatory effect. while the drugs did not inhibit the diarrhea induced by other diarrhogens such as pilocarpine, 5-HT, PGE 2 and sennoside. Therefore, the inhibitory effect of these drugs on ETX-induced diarrhea may not be an action that is produced by their nonspecific effect such as spasmolytic action.

Fletcher et al. $(16,17)$ demonstrated the increased plasma PGs concentration following i.v. administration of ETX in dogs and primates and showed that the therapeutic doses of NSAID given before and after administration of ETX prevented the increase in PGs. Herman and Vane (18) reported an increased release of $P G s$, mainly $P G E_{2}$ and $P G F_{2 x}$, in the renal venous blood during ETX hypotension. Bult et al. described that there was a clear increase in the blood level of 6-keto-PGF $F_{10}$ during ETX-induced hypotension (19) and that ETX may promote the release of arachidonic acid to lead to the biosynthesis of prostacyclin (20). Therefore, it is suggestive that a part of the biological actions of $E T X$ is related to $P G s$ release.

PGs inhibit absorption of water and electrolytes in the jejunum of man and 
animals, cause an increase in sodium and chloride flux from the blood to the intestinal lumen, and therefore, increase the intestinal fluid volume to produce diarrhea (21). Laxatives such as ricinoleic acid, diphenolic laxatives and sennoside are also reported to inhibit absorption of water and electrolytes in the jejunum and colon and increase their transfer from the blood to the lumen which results in increased fluid volume (22). Beubler and Juan (23) proved that diphenolic laxatives increase the $\mathrm{PGE}_{2}$ level in the perfusate of rat colon, and the pretreatment with indomethacin reduces the diarrhogenic effect of diphenolic laxatives. Awouters et al. (10) suggested that NSAID inhibit the diarrhogenic effect of castor oil by depressing $\mathrm{PGs}$ biosynthesis. Therefore, it appears that ETX-induced diarrhea may be attributed partially to the release of PGs, and the inhibition of anti-inflammatory drugs on ETX-induced diarrhea may also be produced by inhibition of PGs biosynthesis.

Ultraviolet erythema in guinea pigs was inhibited potently by acidic NSAID, but not by most of the basic NSAID and SAID which did not inhibit PGs biosynthesis directly (24). A number of investigators verified that erythema formation in the ultraviolet test is caused by the production of $\mathrm{PGE}_{2}(25,26)$ and that intradermal injection of $P G E_{2}$ leads to erythema $(27,28)$. The acute death of rabbits by i.v. injection of arachidonic acid was also inhibited obviously by PGs biosynthesis inhibitors, acidic NSAID, but not by many basic NSAID and SAID. Therefore, it is conceivable that both ultraviolet erythema and acute death by arachidonic acid may be induced by $P G s$ biosynthesis.

Though many evidences mentioned above showed that ETX-induced diarrhea seems to be closely related with increased PGs biosynthesis, our results suggest that this diarrhea could not be explained only by PGs. ETX-induced diarrhea as well as both ultraviolet erythema and acute death was inhibited markedly by aspirin-like drugs of acidic NSAID. Proquazone (29) and GP53633. which are basic compounds and reported to markedly inhibit $P G$ s biosynthesis, also inhibited the ETX-induced diarrhea and the other two reactions. On the other hand, many other basic NSAID and SAID which did not inhibit PGs biosynthesis could potently inhibit ETX-induced diarrhea, but not the other two reactions. Moreover, benoxaprofen, an acidic compound with a weak inhibitory action on PGs biosynthesis (30), was potent and weak to inhibit ETXinduced diarrhea and ultraviolet erythema, respectively. Therefore, it may be considered that the inhibition of ETX-induced diarrhea is produced by mechanisms other than the inhibition of PGs biosynthesis.

It has been proposed that $\mathrm{PGs}$ are mediators of the inflammatory response, and the effect of NSAID is correlated with their ability to inhibit PGs biosynthesis. Some antiinflammatory drugs, however, do not inhibit PGs bioxynthesis directly. The mechanism of ETX-induced diarrhea is not clear, but there was a good correlation between the inhibitory actions on ETX-induced diarrhea and on ultraviolet erythema. Therefore, it is reasonable to believe that the test using ETX-induced diarrhea in mice is a new and desirable method for screening and evaluating anti-inflammatory agents.

\section{References}

1) Pierce, N.F., Carpenter, C.C.J., Elliott, H.L. and Greenough, W.B.: Effects of prostaglandin, theophylline and cholera exotoxin upon transmucosal water and electrolyte movement in the caninic jejunum. Gastroenteology 60, 2232 (1971)

2) Matuchansky, C. and Bernier, J.J.: Effect of prostaglandin $E$ on glucose, water and electroIyte absorption in the lumen jejunum. Ibid 64 , 1111-1118 (1973)

3) Beubler, E. and Juan, H.: The function of prostaglandin in transmucosal water movement and blood flow in the rat jejunum. Naunyn 
Schmiedebergs Arch. Pharmacol. 299, 89-94 (1977)

4) Beubler, E. and Juan, H.: PGE-release blood flow and transmucosal water movement after mechanical stimulation of the rat jejunum mucosa. Ibid 305, 91-95 (1978)

5) Straub, W. and Trendel, E.: Uber die Wirkung des Senna-Infues auf den Dickdarm der Katze. Naunyn Schmiedbergs Arch. Exp. Path. Pharmakol. 175, 528-535 (1934)

6) Lemnens, L. and Borja, E.: The influence of dihydroxyanthracen derivative on water and electrolyte movement in rat colon. J. Pharm. Pharmacol. 28, 498-501 (1976)

7) Nell, G., Forth, W., Overgoff, H., Pfleger, K. and Rummel, W.: Ein-und Ausstrom von Natrium an Dunn-und Dickdarm. Naunyn Schmiedebergs Arch. Pharmacol. 269, 423-424 (1971)

8) Beubler, E. and Juan, H.: Effect of ricinoleic acid and other laxatives on net water flux and prostaglandin $E$ release by the rat colon. J. Pharm. Pharmacol. 31, 681-685 (1979)

9) Beubler, E. and Juan, H.: PGE-mediated laxative effect of diphenolic laxatives. Naunyn Schmiedebergs Arch. Pharmacol. 305, 241-246 (1978)

10) Awouters, E., Niemegeers, C.J.E., Lenaerts, F.N. and Janssen, P.A.J.: Delay of castor oil diarrhoea in rats: a new way to evaluate inhibitors of prostaglandin biosynthesis. J. Pharm. Pharmacol. 30, 41-45 (1978)

11) Thomas, L.: The physiological disturbance produced by endotoxins. Annu. Rev. Physiol. $16,467-490$ (1954)

12) Fletcher, J.R. and Ramwell, P.W.: Lidocaine or indomethacin improves survival in baboon endotoxin shock. J. Surg. Res. 24, 154-160 (1978)

13) Tsurumi, K., Hayashi, M., Hibino, R. and Fujimura, $H_{\text {.: }}$ Testing method for cathartic agents in mice. Folia Pharmacol. Japon. 65, 643-648 (1969) (Abs. in English)

14) Winder, C.V., Wax, J., Burn, V., Been, M. and Rosiere, C.E.: A study of pharmacological influence of ultraviolet erythema in guinea pigs. Arch. Int. Pharmacodyn. Ther. 116, 261292 (1958)

15) Silver, M.J., Hoch, W., Kocsis, J.J., Ingerman, C.N. and Smith, J.B.: Arachidonic acid causes sudden death in rabbits. Science 183, 10851086 (1973)

16) Fletcher, J.R., Ramwell, P.W. and Herman, C.M.: Prostaglandins and the hemodynamic course of endotoxin shock. J. Surg. Res. 20, 589-594 (1976)

17) Fletcher, J.R., Herman, C.M. and Ramwell,
P.W.: Improved survival in endotoxemia with aspirin and indomethacin pretreatment. Surg. Forum 27, 11-12 (1976)

18) Herman, A.G. and Vane, J.R.: Effect of indamethacin on endoyoxin-induced production of prostaglandins in the isolated rabbit jejunum. Adv. Prostaglandin Thromboxane Res. 2, 557560 (1976)

19) Bult, H., Beetens, J., Vercruysse, P. and Herman, A.G.: Blood levels of 6-keto-PGF the stable metabolite of prostacyclin during endotoxin induced hypotension. Arch. Int. Pharmacodyn. Ther. 236, 285-286 (1978)

20) Bult, H., Rampart, M., Van Hove, C. and Herman, A.G.: Effect of endotoxin on biosynthesis of prostacyclin by isolated rabbit peritoneum. Arch. Int. Pharmacodyn. Ther. 242, 288-290 (1979)

21) Forth, W., Rummel, W. and Baldauf, J.: A Wasser-und Elektrolytbewegung am Dunn-und Dickdarm unter dem Einfluss von Laxantien ein Beitrag zur Klarung ihres Wirkungsmechanisms. Naunyn Schmiedebergs Arch. Pharmacol. 254. 18-32 (1966)

22) Nell, G., Overhoff, H., Forth, W., Kulenkampff, $H .$, Specht, W. and Rummel, W.: Influx and efflux of sodium in jejunum and colonic segments of rats under influence of oxyphenisatin. Ibid 277, 53-60 (1973)

23) Beubler, E. and Juan, H.: is the effect of diphenolic laxatives mediated via release of prostaglandin E. Experientia 34, 386-387 (1978)

24) Danon, A. and Assouline, G.: Inhibition of prostaglandin biosynthesis by corticosteroids requires RNA and protein synthesis. Nature $273,552-554(1978)$

25) Sondergraad, J. and Greaven, M.W.: Pharmacologic studies in inflammation due to exposure to ultraviolet radiation. J. Pathol. 101, 93-97 (1970)

26) Methur, G.P. and Ghandi, V.M.: Prostaglandin in human and albino skin. J. Invost. Dermatol. 58, 291-295 (1972)

27) Synder, D.S.: Effect of topical indomethacin on UVR-induced redness and prostaglandin $E$ levels in sunburn guinea pigs skin. Prostaglandins 11, 631-643 (1976)

28) Otomo, S., Higuchi, S., Tanaka, M., Gotoh. Y., Osada, Y. and Ohzeki, M.: Effects of antiinflammatory drugs on the arachidonic acid induced erythema in guinea pigs. Folia Pharmacol. Japon. 78, 185-190 (1981) (Abs. in English)

29) Schweitzer, A. and Brune, K.: Salicylic acid and proquazone: the differences in absorption 
and biodistribution explain their different profile of side effects. In Perspective in Inflammation, Edited by Wiloughby, D.A., Giroud, J.P. and Velo, G.P., p. 353-359. University Park Press. Baltimore (1977)
30) Dawson, W., Boot, J.R., Harvey, J. and Walker, J.R.: The pharmacology of benoxaprofen with particular reference to effects on lipoxygenase product formation. Eur. J. Rheumatol. Inflamm. 5, 61-68 (1982) 